\title{
Developing Communication Skills of Students - An Analysis on Pragmatic Performance
}

\author{
Dr. R. Abilasha ${ }^{1^{*}}$, Dr. M. Ilankumaran ${ }^{2}$ \\ ${ }^{I}$ Assistant Professor of English, Holy Cross College of Arts and Science (Autonomous), Nagercoil, Tamilnadu, \\ India \\ ${ }^{2}$ Professor of English, Noorul Islam Centre for Higher Education, Kumaracoil, Thuckalay, Tamilnadu, India \\ *Corresponding Author: Dr. R. Abilasha, Assistant Professor of English, Holy Cross College of Arts and \\ Science (Autonomous), Nagercoil, Tamilnadu, India
}

\begin{abstract}
English is an international language and it was proved by many native and non-native speakers all around the world. It is also being considered the global language because it is the common means for interaction between various countries. The use of English as common language occupies an important place in the field of education in our country. It is very important that the learners of English should highly focus on the use of communication. The ultimate aim of teaching language is to develop the communicative competence. The communicative competence is considered an instrument used for communication, and pragmatics is the way in which meaning is conveyed through communication. Pragmatic competence refers to the ability to understand and convey the meanings which are more accurate and appropriate for the social and cultural circumstances in which the communication occurs. In short, pragmatics is about the culture and the communication. Though English is used in different levels of communication, the speaker must know many pragmatic elements, to develop the coherency and the ability to react in different situations. For that, development of pragmatic ability should be considered as one of the primary goals in the field of education.
\end{abstract}

Keywords: Communication, Communicative skills, Pragmatism, Pragmatic skills, Pragmatic Competence, Language Teaching

\section{INTRODUCTION}

English is the language which is followed throughout the world and is considered to be an important language in the whole country. It is considered to be the queen of languages and occupies the position as the royal language. Moreover, English language is gaining more prominence over all other regional languages. English is the most common means of communication. It maintains a prominent place in the field of education system too. The study of the target language is considered the passport for employment. After independence, there raised a number of questions regarding the place of English in India. Some leaders argued that English has to be uprooted and some others favored the presence of English in India. Even, Mahatma Gandhi said, "It has put a severe strain upon the Indian students and made us imitators. The English language is necessary for imbibing ideas of liberty and developing accuracy of thought" (Magdalin, 2). Moreover, in the words of Pt.Nehru, "One hundred and fifty years of intimate contact has made English an integral part of our educational system and this cannot be changed without injury to the cause of education in India" (Magdalin, 2). English is the most common means of communication in many fields. So, one has to be fluent in English language for that, the learners have to develop the communicative competence through pragmatism. The main purpose of teaching language must be to develop the communicative competence. Human communication is utterly unique for its extensive use of language through skills. Communication is useful to all mankind in various aspects.

\section{Pragmatics}

Pragmatics is the branch of linguistics which deals with the study of language. It studies the ways, how the context contributes to meaning. It also includes speech acts, conversational utterance and talk in interaction. Morris has been defined pragmatics as "... the discipline that studies the relations of signs to interpreters, while semantic studies the relations of signs to the objects to which the signs are 
applicable" (Deda, Nivis, 2). Pragmatism is a reasonable and logical way of doing things or of thinking about problems which are based on dealing with specific situations instead of ideas and theories. A philosophical movement or system having various forms but generally, stressing the practical consequences as consulting the essential criterion in determining the meaning, truth or value. It is the outcome of practical experiences of life. Pragmatism does not believe in fixed and eternal values. According to pragmatism, no idea will remain true for ever. It is humanistic in nature because it is concerned more with human life. Therefore, it is also called 'humanism'. The people, who are practical in nature, are called pragmatists. When a problem arises to them, they try to solve them from the practical point of view.

The central theme of pragmatism is action or activity. Pragmatism has been derived from the Greek word "pragmatikos", which means practicability. Principles are derived from the activity done and hence it is also known as experimentalism. The fundamental start of pragmatism is "change". It is closely connected with human life and welfare. It is the product of practical experiences of life. Pragmatic language refers to the social language skills used in the day to day interactions with others. It includes what to say, how to say and the body language whether the appropriateness is given to the situation. It also implies the ability to use language for different purposes such as to greet others and make comments. Social language includes the ability to understand the rules of conversation. The learner may be an eloquent speaker in the mother tongue but gets hindrance while speaking in the target language. It is important to enrich the competence in this competitive world. Some may say the words clearly and use long, complex sentence even with correct grammar but still have some communication problems. It is because the rule of the social language was not mastered by the learners properly and this social communication is known pragmatics. Social communication is known as pragmatics. Social communication is important to build the social relationship with other people. Levinson defines pragmatics as "the study of language from a functional perspective that attempts to explain facets of linguistic structure by reference to non-linguistic pressures and causes" (Aquino, 141).

\subsection{Pragmatic Skills}

Pragmatics involves three major communication skills. Using the language for different purposes such as greeting, demanding, requesting is one of the pragmatic skills applied. Changing the language style according to the needs of a listener or a situation is the second pragmatic skill. Following certain rules for the conversations and for story telling is another pragmatic skill, which is very essential for the learners to enhance their communicative competence socially. Pragmatic problem may create complex among the learners in the society and also among the peers. It is better to enhance the competence to avoid such problems. Communication is the process of conveying the thoughts, intentions, emotions, feelings and facts. It should be conveyed by the sender effectively and understood by the receiver properly.

\subsection{Pragmatic Skill also Includes}

- Using the language in the appropriate time.

- Knowing when to answer a question asked to the learners.

- Being able to participate in a conversation with the other speaker.

- The ability to identify and react to the non-verbal aspect of language.

- The awareness to introduce a topic and makes it sure that it was understood by the listener.

- The ability to maintain a particular topic.

- The ability to maintain the appropriate eye contact during conversation.

- The ability to identify how to behave towards different communicative partners.

Social language also includes the verbal communication skills or conversation skill and non-verbal communication.

\subsection{Verbal Communication}

The term verbal denotes the use of words. The words used to communicate may be in spoken or oral form. It occurs by the process of uttering words, through telephones or face to face talks. 


\subsection{Non-Verbal Communication}

Non-Verbal Communication involves neither written nor spoken words. Non verbal communication is otherwise known as body language. People can communicate not only through words, but also through means other than words. The various categories of non verbal communication is

- Kinesics

- Oculesis

- Haptics

- Proxemics

- Chronemics

- Paralinguistics

- Physical Appearance

\subsubsection{Kinesics}

It is the way by which communication can be communicated through facial expressions and gestures. In short, the way the body communicates by its physical movement.

\subsubsection{Oculesics}

Oculesics is a technical term used for the eye contact in non-verbal communication. It is the study of eye contact as a form of body language.

\subsubsection{Haptics}

Haptic communication is the means by which people communicate through touch and it is the process of recognizing objects through touch.

\subsubsection{Proxemics}

Proxemics communication is about the measurable distance between the speakers when they interact with each other.

\subsubsection{Chronemics}

It is about the role of time in communication.

\subsubsection{Paralinguistics}

Paralinguistics is the way by which the learners use the voice in uttering words. It is other than the pitch, speed, volume, tone etc.

\subsubsection{Physical Appearance}

Physical appearance always contributes towards the learners understanding in communication written communication.

\section{Pragmatic Competence}

Pragmatic competence is a fundamental aspect of more communicative competence. It is an ability to use the language and interpret easily without any hesitation. Dealing the matter sensibly and realistically in a way that is based more on practical than theory. The ability to understand the other speaker's idea what they mean while conveying is meant as pragmatic competence. As a learner of target language, one has to be well equipped with the pragmatic competence. Using the target language in an appropriate way is vital for the immersion into an English speaking society and culture. It is better to develop the communicative competence as well as the grammatical competence. English is considered Lingua Franca. Pragmatic competence of the target language helps the learners to be the better users of the target language. Lack of these pragmatic performance makes the learners get into trouble and it leads the user in committing errors while communication. So, it is better to enhance the pragmatic competence.

\section{Pragmatic aims of Education}

According to pragmatism, the aims of education are 


\subsection{Growth and Creation of New Values}

Pragmatism does not have any kind of fixed aims or targets of education. The general educational aim of the pragmatist is just the creation of new values. So the main task of the educator is to put the educated into a position of developing values for himself.

\subsection{Activities and Experience}

For creating or developing new values activities and experience are essential. Therefore, educations have to provide physical, intellectual, moral and aesthetic activities as the sources for developing the creation of values.

\subsection{Emphasis on Personal and Social Adjustment}

The aim of the education must make the learners understand the aspects developed not for their own sake but also for all individuals and social needs of man.

\subsection{Reconstruction of Experience}

Pragmatism emphasizes the learner's adaptation to environment, construction and reconstruction of experimental and development of experiences and development of capacities to control the environment.

\subsection{All round Development}

According to pragmatism, the learners are the all rounder performers and it was the main aim of education. The individual must develop physically, mentally, socially, morally and above all aesthetically.

\section{Ways to Enhance Pragmatic Competence}

Practice is the basic way to enhance the pragmatic competence. Practice makes the learner better in all matters. Making use of all simple opportunities enhances the pragmatic competence. According to the pragmatic principle, bookish knowledge is condemned and self learning through self effort is emphasized. Productive practical activities have to be encouraged for the learners so that the learners gain the confidence to face the problems boldly and successfully and attains all the challenges of this modern world. So, self learning will be the beneficial one for the learners to enhance their pragmatics competence.

Activities or learning by actions give rise to many ideas. Fluency in communication or speech cannot be given to the learners directly by anyone. The learners have to practice the skill regularly and continuously until the learners must make use of the opportunities given to them until the goal is attained. Though communication is a two way process interrogatives can be often used while interacting with each other which enhance the pragmatic competence. Listening keenly to the native speakers of English also enhance a lot in improving the communicative competence. Watching English news on television channels and listening to English songs are also authentic to enhance the competence of the learners. Moreover, courage and confidence make a better conversation and everyday practice of skills makes it more perfect.

\section{Data Analysis of Students' Performance}

An analysis for two sets of language learners was conducted. They are English medium students and the vernacular students. The observation for each and every word syntax structure is analyzed before and after the practice of pragmatic competence. First, the task of reading was given to the two sets of learners. The way they read was analyzed. The pronunciation, stress, intonation, syntax and structure were clearly identified. Then, after giving the pragmatic competence again, both the sets of the students were observed and found a lot of changes in their performance.

The pragmatic performance is studied between the English medium students and the vernacular students. Syntax, coherence and use of context of the Tamil medium students differ from those of English medium students. The slang and the accent used by the Tamil medium students differ a lot from those of English medium students. For that, listening skills play a major role to change the accents of the Tamil medium students. Making ways to interact with each other, will also improve the communication skills. Various methods and techniques such as storytelling, performing, role modeling and debates should be given to the learners of Tamil medium to improve the communication skills. 


\subsection{Analysis of Students' Performance}

Table 1 gives and Figure 1 shows the response of the respondents to the questions on pragmatic performance of the vernacular students is low. 2 students agreed strongly, 2 students agreed, one was neutral, 2 students disagreed and student strongly disagreed the question regarding the communicative capability of the vernacular students. 3 students strongly agreed where as 1 agreed and 2 remained neutral, 3 students disagreed and 1 strongly disagreed.

Table1. Response Based on Tamil medium

\begin{tabular}{|c|c|c|c|c|c|c|c|}
\hline Sl. No. & Variables & Strongly Agree & Agree & Neutral & Disagree & Strongly Disagree & Total \\
\hline 1. & Performance & 2 & 2 & 1 & 2 & 3 & 10 \\
\hline 2. & Communication & 3 & 1 & 2 & 3 & 1 & 10 \\
\hline
\end{tabular}

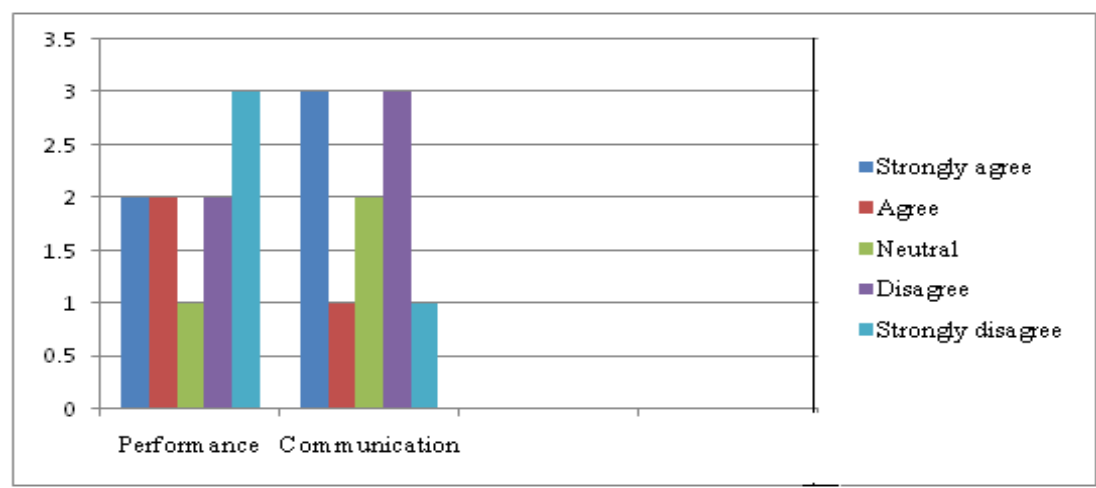

Figure1. Students Studying in Tamil Medium

Table 2 gives and Figure 2 shows the information regarding the question on students of English medium perform well in their communicative process, 4 students strongly agreed, 1 agreed, 2 of them were in neutral state, 1 disagreed and 2 strongly disagreed.

To the question, pragmatic performance is more in English medium students than the Tamil medium students, 3 of them agreed strongly, 2 agreed, one was in neutral state, 2 disagreed and 2 strongly disagreed.

Table2. Responses Based on English Medium

\begin{tabular}{|c|c|c|c|c|c|c|c|}
\hline Sl. No. & Variable & Strongly Agree & Agree & Neutral & Disagree & Strongly Disagree & Total \\
\hline 1. & Communicative Process & 4 & 1 & 2 & 1 & 2 & 10 \\
\hline 2. & Pragmatic Performance & 3 & 2 & 1 & 2 & 2 & 10 \\
\hline
\end{tabular}

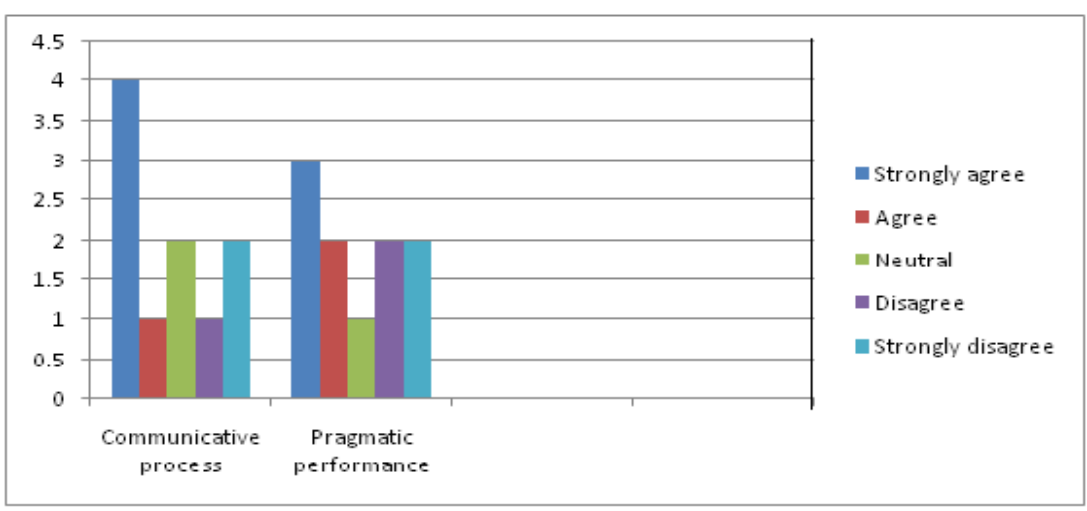

Figure2. Students Studying in English Medium

\section{FINDINGS OF THE STUDY}

- The vernacular medium learner's performance was lower than the English medium students because of the mother tongue influence.

- The vernacular medium learners were not interested in getting themselves involved in the activities provided to them to enhance their communication skills because of hesitation.

- The vernacular learners have to be given more opportunities for developing their skills in the learning process. 
- Special concern to develop their competence has to be encouraged.

- Enhancing communicative activities must be given to them to practice regularly till the goal is attained.

\section{SUgGeStions}

Activities to enhance the communicative competence through pragmatism were given to the learners. The learners' improvement was better than what it was before the practice. The outcome, thus, indicates that practice makes the learners perfect. The competence given to them is very strong. The overall suggestion is that the communicative competence will improve, when the learners are given more chance to use the target language in an authentic context.

\section{CONCLuSion}

The different ways to enhance the communicative competence through pragmatism helps the learners to become more effective and fluent in the target language. The educational system has to suggest more teaching learning activities apt for the learners to enrich their communicative competence. Communicative activities have to be encouraged in the classrooms in order to develop pragmatic competence. Teaching pragmatics to the learners in the deeper level develops the learner's critical thinking and makes them realize that the words are not just the words, but something great.

\section{REFERENCES}

[1] Aquino, De Carla, Pragmatic Competence: How Can It be Developed in the Foreign Language Classroom? BELT Journal, Porto Alegre, Volume 2,Number 2. pp. 140-153, 2011

[2] Deda, Nivis, The Role of Pragmatics in English Language Teaching Pragmatic Competence, Academic Journal of Interdisciplinary Studies, Volume 2, Number 4, May 2013, ISSN 2281-3993.

[3] Venugopalan P \& Ilankumaran, M. Communication Skills in English through Developmental Speaking, Contemporary Discourse, Peer-Reviewed, Volume III, Issue II-July, 2012, ISSN: 0976-3686.

[4] Behrmann, M. \& Penn, C., (1984), Non- Verbal Communication of Aphasic Patients, British Journal of Communication, Volume 19, pp. 155-168.

\section{AUTHOR'S BIOGRAPHY}

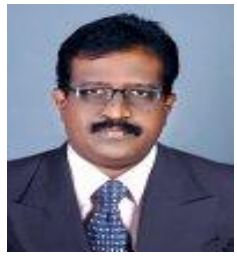

Dr. M. Ilankumaran, having English Language Teaching (ELT) as specialization in his $\mathrm{M}$. Phil and $\mathrm{Ph}$. D with an experience of more than two and a half decades at various levels, is at present working as a Professor and Research Programme Coordinator in English in Noorul Islam Centre for Higher Education, Kumaracoil, Tamilnadu. With all earnestness, he conducts workshops for the English fraternity on Effective Communication Skills and organizes conferences on English Language and Literature. $\mathrm{He}$ is a visiting faculty teaching 'Applied Linguistics' and 'English for Communication'. He guides scholars at M.Phil and Ph.D level and produced many. Besides being an able administrator, he, to his credit, has published several articles on ELT in Indexed, Refereed journals of at National and International levels.

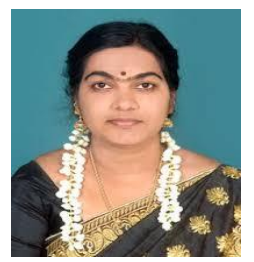

Dr. R. Abilasha has two decades of teaching experience in imparting English Grammar and language. She is currently teaching courses on General English Literature and Language to the UG students in Holy Cross College of Arts and Science (Autonomous), Nagercoil. Having completed Ph. D in ELT, she guides students and scholars in the areas of English Language Teaching and Comparative Literature. She is a committed language teacher who has ardent fervor in uplifting the communicative capacity of the students. She has published articles on ELT in Indexed, Refereed journals of at National and International levels.

Citation: Dr. R. Abilasha, Dr. M. Ilankumaran. "Developing Communication Skills of Students - An Analysis on Pragmatic Performance" International Journal on Studies in English Language and Literature (IJSELL), vol 6, no. 7, 2018, pp. 26-31. doi:http://dx.doi.org/10.20431/2347-3134.0607004.

Copyright: (C) 2018 Authors. This is an open-access article distributed under the terms of the Creative Commons Attribution License, which permits unrestricted use, distribution, and reproduction in any medium, provided the original author and source are credited. 